\title{
The Chemistry of the Postpharyngeal Gland of Female European Beewolves
}

\author{
Erhard Strohm • Gudrun Herzner • \\ Martin Kaltenpoth • Wilhelm Boland • Peter Schreier • \\ Sven Geiselhardt • Klaus Peschke • Thomas Schmitt
}

Received: 31 January 2007 / Revised: 31 January 2008 / Accepted: 8 February 2008 / Published online: 16 April 2008

(C) The Author(s) 2008

\begin{abstract}
Females of the European beewolf, Philanthus triangulum, possess a large glove-shaped gland in the head, the postpharyngeal gland (PPG). They apply the content of the PPG to their prey, paralyzed honeybees, where it delays fungal infestation. Here, we describe the chemical composition of the gland by using combined GC-MS, GC-FTIR, and derivatization. The PPG of beewolves contains mainly long-chain unsaturated hydrocarbons (C23-C33), lower amounts of saturated hydrocarbons (C14-C33), and minor amounts of methyl-branched hydrocarbons (C17-C31). Additionally, the hexane-soluble gland content is comprised of small amounts of an unsaturated C25 alcohol, an unknown sesquiterpene, an octadecenylmethylester, and several long-chain saturated (C25, C27) and unsaturated (C23-C27) ketones, some of which have not yet been reported as natural products. Surprisingly, we found a
\end{abstract}

E. Strohm $(\bowtie) \cdot$ G. Herzner $\cdot$ M. Kaltenpoth

Department of Zoology, University of Regensburg,

93040 Regensburg, Germany

e-mail: erhard.strohm@biologie.uni-regensburg.de

E. Strohm • G. Herzner • M. Kaltenpoth - T. Schmitt

Department of Animal Ecology and Tropical Biology,

Theodor-Boveri-Institute, University of Würzburg,

97074 Würzburg, Germany

W. Boland

Max-Planck-Institute for Chemical Ecology,

Jena, Germany

P. Schreier

Department of Food Chemistry, University of Würzburg,

97074 Würzburg, Germany

S. Geiselhardt $\cdot$ K. Peschke $\cdot$ T. Schmitt

Department of Evolutionary Biology and Animal Ecology,

Faculty of Biology, University of Freiburg,

Freiburg, Germany dimorphism with regard to the major component of the PPG with some females having (Z)-9-pentacosene, whereas others have (Z)-9-heptacosene as their predominant component. The biological relevance of the compounds for the prevention of fungal growth on the prey and the significance of the chemical dimorphism are discussed.

Keywords Antifungal · Crabronidae - GC-FTIR . Hymenoptera Philanthus triangulum . Postpharyngeal gland $\cdot \mathrm{PPG} \cdot$ Sphecidae

\section{Introduction}

Hymenoptera possess a huge variety of exocrine glands (e.g., Hölldobler and Wilson 1990). The chemistry and function of different types of these have been studied for a number of social species, whereas comparatively little is known from solitary bees and wasps. Recently, a postpharyngeal gland (PPG) has been described from a species of digger wasp (Strohm et al. 2007), the European beewolf, Philanthus triangulum Fabricius 1775 (Hymenoptera: Crabronidae, formerly Sphecidae, Melo 1999). The occurrence of this gland is surprising since the PPG was assumed to be restricted to ants (Hölldobler and Wilson 1990; Schoeters and Billen 1997; Lenoir et al. 1999) where it functions in generating the colony odor (e.g., Hefetz et al. 1992, 1996; Soroker et al. 1994, 1995, 1998; Vienne et al. 1995; Dahbi et al. 1998; Lenoir et al. 1999, 2001; Oldham et al. 1999; Soroker and Hefetz 2000; for a review of other proposed functions, see Eelen et al. 2006).

In beewolves, the PPG has a unique function in protecting the larval provisions from microbial attack (Strohm and Linsenmair 2001; Herzner and Strohm 2007; Herzner et al. 2007a). Female European beewolves hunt 
and paralyze honeybees, bring them to their nest burrow, and provision one to six bees in a brood cell as larval food for one progeny. Due to the humid and warm conditions in the brood cell, the highly nutritive provisions are prone to detrimental microbial attack (Strohm and Linsenmair 2001). Early fungus infestation inevitably destroys the food resources, and larvae are killed by fungal toxins or starve to death. Observations in special cages (Strohm and Linsenmair 1994-1995) revealed that beewolf females intensively lick the bodies of the paralyzed bees and apply the secretion from the PPG to the bees' surface (Strohm and Linsenmair 2001; Herzner et al. 2007a). This treatment has the effect of delaying fungus growth for 2 to 3 days, which is a highly relevant effect given the short larval feeding period of only 8 to 11 days. The primary mechanism of this delay is not a direct chemical effect of the secretion on fungi, but the prevention of water condensation on the bees that in turn impairs the germination and growth of fungal spores (Herzner and Strohm 2007). Male European beewolves also have a PPG that is even larger than in females (Herzner et al. 2007b). However, it serves as a reservoir for the scent marking pheromone that males apply to their territories to attract females (Kroiss et al. 2006).

Despite the advanced understanding of the function of the secretion of the PPG of female European beewolves, there has been no detailed investigation of its chemistry. Therefore, we analyzed the chemical composition by using combined gas chromatography-mass spectrometry (GC-MS), gas chromatography-Fourier transform infrared spectroscopy (GC-FTIR), fractionation, and derivatizations.

\section{Materials and Methods}

Sampling Beewolf females were taken either from a field population close to the Biocenter of the University of Würzburg, Germany, or from a laboratory population kept at the University of Würzburg (daughters of field caught females). They were all mated with actively provisioned nests with honeybees and were between 1 and 4 weeks old. To identify the chemicals of the PPG, females that were freshly killed by $\mathrm{CO}_{2}$ were decapitated, and their PPGs were removed from the heads by grasping the hypopharynx with tweezers and gently pulling the attached gland out through the mouth (Strohm et al. 2007). The glands were immersed immediately in $0.25 \mathrm{ml} n$-hexane (Fluka Chemie $\mathrm{GmbH}$, Buchs, Switzerland) that had been distilled prior to use. For the identification of the components in the PPG, the glands of four females were pooled. This enabled us to identify minor components that were not reliably detectable in the extracts of individual PPGs. In order to have an easier method to obtain the content of the PPG, we investigated whether extracts of whole heads differed in composition from dissected glands. There was a large amount of hydrocarbons in the PPG, and extracts of entire heads were identical to extracts of the dissected glands. There were no additional peaks detectable and the proportions were the same (see Herzner et al. 2007b for an analogous procedure for male PPGs). Thus, as an easier alternative to the dissection of the PPG, entire heads were extracted. To obtain data on PPG content variability, we analyzed individual extracts made from the heads of 37 females. Heads of freshly killed females were cut off and extracted in distilled hexane for $4 \mathrm{~h}$. An internal standard (octadecane, Sigma, St Louis, MO, USA) was added to assess the absolute amount of compounds in the PPG (although octadecane could be detected in pooled samples, it was not detectable in individual samples and was therefore employed as an internal standard).

Identification Identification of the chemicals was accomplished by GC-MS. Head extracts were fractionated by solid phase extraction (SPE, Chromabond, unmodified silica, $3 \mathrm{ml}, 500 \mathrm{mg}$, Macherey-Nagel, Düren, Germany) with hexane as the first and dichloromethane as the second eluent to separate nonpolar and polar fractions. Alkanes were characterized by comparison of mass spectra and retention indices with those of purchased standard alkanes (Aldrich, Deisenhofen, Germany). Corresponding alkenes were tentatively identified by their typical mass spectra, their retention indices, and (depending on availability) with commercially available (Aldrich) and synthesized standards. Dimethyl disulfide (DMDS) derivatization was carried out to determine the position of double bonds according to the method of Dunkelblum et al. (1985). The configurations of the double bonds were determined by using GC-FTIR (Attygalle 1994). Methyl-branched alkanes were identified by using MS databases and diagnostic ions, and by determining retention indices (Carlson et al. 1998). Details on the identification of polar compounds are given in the results section.

For the identification of the hydrocarbons, we used a Hewlett Packard HP 6890 Series GC System coupled to a Hewlett Packard HP 5973 Mass Selective Detector (Agilent Technologies, Böblingen, Germany). The GC was equipped with a DB-1 fused silica capillary column (30 $\mathrm{m} \times 0.25 \mathrm{~mm}$ i.d., $0.25 \mu \mathrm{m}$ film thickness; J \& W, Folsom, CA, USA). Temperature was programmed from $100^{\circ} \mathrm{C}$ to $300^{\circ} \mathrm{C}$ with a $6^{\circ} \mathrm{C} / \mathrm{min}$ heating rate, held for $20 \mathrm{~min}$ at $300^{\circ} \mathrm{C}$. Helium was used as carrier gas with a constant flow of $1 \mathrm{ml} / \mathrm{min}$. Injection was carried out at $300^{\circ} \mathrm{C}$ in the splitless mode for $2 \mathrm{~min}$. The electron impact mass spectra (EI-MS) were recorded with an ionization voltage of $70 \mathrm{eV}$ and a source temperature of $230^{\circ} \mathrm{C}$. The software ChemStation (Agilent Technologies) for windows was used for data acquisition. 
GC-FTIR spectra were obtained by using an HP 5890 GC (Agilent Technologies) coupled to an FTS 575C Tracersystem (BioRad, Hercules, CA, USA). The GC was equipped with the same column as described above. Temperature was programmed from 80 to $270^{\circ} \mathrm{C}$ with a $4^{\circ} \mathrm{C} / \mathrm{min}$ heating rate. Helium was used as carrier gas with a constant flow of 1-2 $\mathrm{ml} / \mathrm{min}$. Injections were carried out by using a split/splitless injector at $250^{\circ} \mathrm{C}$ in the splitless mode for $60 \mathrm{~s}$. Injection volume was $0.1 \mu \mathrm{l}$. IR spectra were recorded by scanning 256 times in a frequency range from 4,000 to $700 \mathrm{~cm}^{-1}$ with a resolution of $1 \mathrm{~cm}^{-1}$. Data system was a Dell Optiplex GX110-PC with BioRad WinIR Pro (Version 2.7) Tracer Software and Sadtler IRSearchMaster.

Data Handling and Statistical Analysis Because the relative amounts of compounds constitute compositional data, they were transformed to logcontrasts according to Aitchison (1986): $Z_{i j}=\log _{10}\left(Y_{i j} / \mathrm{g}\left(Y_{j}\right)\right)$ where $Z_{i j}$ is the standardized peak area $i$ for individual $j, Y_{i j}$ is the peak area $i$ for individual $j$, and $g\left(Y_{j}\right)$ is the geometric mean of all peaks for individual $j$, prior to statistical analysis. Several peaks had to be combined for the quantitative analysis of individuals because they were not always clearly separated in the chromatograms. To test for differences in the proportions of components between groups, we subjected the transformed data to exact tests for two independent groups (SPSS 13.0, SPSS Inc. 2004).

\section{Results}

Identification and Analysis of Hydrocarbons in the $P P G$ The chromatograms of the crude hexane extracts of the PPG showed a total of 53 peaks that represented 62 different compounds (Fig. 1, Table 1). The mean amount of all compounds was $337 \pm 292 \mu \mathrm{g}$ (minimum, $36.7 \mu \mathrm{g}$; maximum, 1,410 $\mu \mathrm{g}, N=37)$. All alkanes as well as $(Z)$ 9-tricosene, $(Z)$-9-pentacosene, and (Z)-9-heptacosene were identified by comparison of mass spectra and retention indices with those of available standards. The location and configuration of double bonds of other alkenes were determined with DMDS derivatives and GC-FTIR data (band at $721 \mathrm{~cm}^{-1}$ : cis configuration of $\mathrm{RCH}=\mathrm{CHR}^{\prime}$; Attygalle 1994). Some components could, however, not be completely characterized (location of methyl groups or double bond, configuration of double bond) due to the small amounts in the extracts. One component could not be identified at all. There were more unsaturated $(81.5 \%)$ than saturated compounds in the nonpolar fraction of the PPG extract from beewolf females.

Identification of the Constituents in the Polar Fraction The polar fraction contained a group of uncommon constituents.

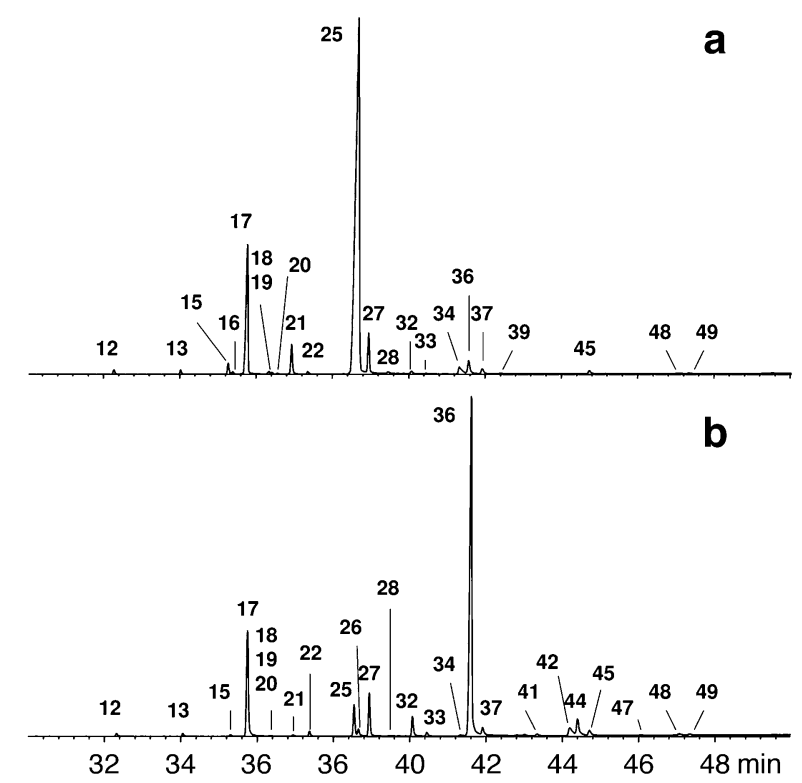

Fig. 1 Total ion chromatograms of the hexane extract of the PPG from individual female European beewolves, Philanthus triangulum, with a (Z)-9-pentacosene (C25-type) and b (Z)-9-heptacosene (C27type) as the predominant hydrocarbon peak. Numbers correspond to the numbers in the peak list (Table 1). Some compounds listed in Table 1 were present in quantities too low to be visible in these chromatograms

Hydrogenation of double bonds with $\mathrm{H}_{2}$ and palladium on carbon (Attygalle 1998) as well as DMDS adducts were used to obtain sufficient information by mass spectrometry to identify these compounds. 18-Heptacosen-10-one was identified by comparison with an already published mass spectrum (Yasui et al. 2003). The mass spectrum of this compound showed a molecular ion of $\mathrm{m} / \mathrm{z} 392$ and two diagnostic fragment ions at $m / z 155$ for $\left[\mathrm{C}_{9} \mathrm{H}_{19}-\mathrm{CO}\right]^{+}$and at $\mathrm{m} / z 265$ for $\left[\mathrm{C}_{17} \mathrm{H}_{33}-\mathrm{CO}\right]^{+}$indicating the carbonyl position at $\mathrm{C} 10$. After hydrogenation of this unsaturated ketone, the resulting 10-heptacosanone as well as the 10heptacosanone of the untreated extract showed identical mass spectra $\left(\mathrm{m} / \mathrm{z}\right.$ : $155\left[\mathrm{C}_{9} \mathrm{H}_{19}-\mathrm{CO}\right]^{+}, 267\left[\mathrm{C}_{17} \mathrm{H}_{35}-\mathrm{CO}\right]^{+}$, $394 \mathrm{M}^{+}$) and identical retention indices $(2,868)$ with that already published by Yasui et al. (2003). 14-Tricosen-6-one was characterized by its diagnostic masses $\left(\mathrm{m} / \mathrm{z}: 99\left[\mathrm{C}_{6} \mathrm{H}_{11^{-}}\right.\right.$$\left.\mathrm{CO}]^{+}, 265\left[\mathrm{C}_{17} \mathrm{H}_{33}-\mathrm{CO}\right]^{+}, 336 \mathrm{M}^{+}\right)$. Also, hydrogenated 14tricosen-6-one was tentatively identified as 6-tricosanone by comparison with a commercially available MS library (NIST 2.0, Stein et al. 2001). The double bond positions in these and additional unsaturated ketones were determined from mass spectra of DMDS adducts. Additionally, three unsaturated and one saturated ketone were tentatively identified as 15-tetracosen-7-one, 16-pentacosen-8-one, 17hexacosen-9-one, and 8-pentacosanone. The corresponding alcohol 16-pentacosen-8-ol was tentatively identified by its diagnostic masses after hydrogenation of the polar fraction 
Table 1 List of compounds in the postpharyngeal gland of females of the European beewolf, Philanthus triangulum

\begin{tabular}{|c|c|c|c|}
\hline Peak No. & RI & Compound Name & Diagnostic MS Ions \\
\hline 1 & 1400 & Tetradecane $\mathrm{a}^{\mathrm{a}}$ & 198 \\
\hline 2 & 1500 & Pentadecane $^{\mathrm{a}}$ & 212 \\
\hline 3 & 1600 & Hexadecane $^{\mathrm{a}}$ & 226 \\
\hline 4 & 1700 & Heptadecane $^{\mathrm{a}}$ & 240 \\
\hline 5 & 1710 & X-Methylheptadecane & - \\
\hline 6 & 1800 & Octadecane $\mathrm{a}^{\mathrm{a}}$ & 254 \\
\hline 7 & 1814 & X-Methyloctadecane & - \\
\hline 8 & 1900 & Nonadecane $^{\mathrm{a}}$ & 268 \\
\hline 9 & 1906 & Sesquiterpene & $41,69,81,93,107,120,133,222$ \\
\hline 10 & 2000 & Eicosane $^{\mathrm{a}}$ & 282 \\
\hline 11 & 2080 & (Z)-9-Octadecenylmethylester ${ }^{\mathrm{a}}$ & $222,264,296$ \\
\hline 12 & 2100 & Heneicosane $\mathrm{a}^{\mathrm{a}}$ & 296 \\
\hline 13 & 2200 & Docosane $^{\mathrm{a}}$ & 310 \\
\hline 14 & 2267 & $\Delta$-X-Tricosene & 322 \\
\hline 15 & 2273 & $(Z)-9$-Tricosene $\mathrm{a}^{\mathrm{a}}$ & 322 \\
\hline 16 & 2286 & $\Delta$-7-Tricosene & 322 \\
\hline 17 & 2300 & Tricosane $e^{a}$ & 324 \\
\hline 18 & 2338 & 11-; 9-Methyltricosane & $168 / 169,196 / 197 ; 140 / 141,224 / 225$ \\
\hline 19 & 2343 & 7-Methyltricosane & $112 / 113,252 / 253$ \\
\hline 20 & 2352 & 5-Methyltricosane & $84 / 85,280 / 281$ \\
\hline 21 & 2371 & $\Delta$-X-Tetracosene & 336 \\
\hline 22 & 2400 & Tetracosane $\mathrm{e}^{\mathrm{a}}$ & 338 \\
\hline 23 & 2436 & $\Delta$-14-Tricosen-6-one & $99,115,127,181,265,336$ \\
\hline 24 & 2464 & $\Delta, \Delta$-X,Y-Pentacosadiene & 348 \\
\hline 25 & 2471 & $(Z)-9-$ Pentacosene $^{\mathrm{a}}$ & 350 \\
\hline 26 & 2492 & $\Delta$-Pentacosene & 350 \\
\hline 27 & 2500 & Pentacosane $\mathrm{a}^{\mathrm{a}}$ & 352 \\
\hline 28 & 2537 & 13-; 11-; 9-Methylpentacosane & $196 / 197 ; 168 / 169,224 / 225 ; 140 / 141,252 / 253$ \\
\hline 29 & 2538 & $\Delta$-15-Tetracosen-7-one & $94,113,141,181,195,265,350$ \\
\hline 30 & 2543 & 7- Methylpentacosane & $112 / 113,280 / 281$ \\
\hline 31 & 2554 & $\Delta$-16-Pentacosen-8-ol & 67,348 \\
\hline 32 & 2572 & (Z)-9-Hexacosene & 364 \\
\hline 33 & 2600 & Hexacosane $\mathrm{a}^{\mathrm{a}}$ & 366 \\
\hline 34 & 2639 & $\Delta$-16-Pentacosen-8-one & $127,155,195,209,265,364$ \\
\hline 35 & 2668 & Pentacosan-8-one & $127,143,155,267,283,366$ \\
\hline 36 & 2672 & $(Z)-9-$ Heptacosene $\mathrm{a}^{\mathrm{a}}$ & 378 \\
\hline 37 & 2700 & Heptacosane $^{a}$ & 380 \\
\hline 38 & 2714 & NI & - \\
\hline 39 & 2735 & 13-; 11-; 9-Methylheptacosane & $196 / 197,224 / 225 ; 168 / 169,252 / 253 ; 140 / 141,280 / 281$ \\
\hline 40 & 2740 & $\Delta$-17-Heptacosen-9-one & $141,169,209,223,265,378$ \\
\hline 41 & 2800 & Octacosane $^{\mathrm{a}}$ & 394 \\
\hline 42 & 2840 & $\Delta$-18-Heptacosen-10-one & $155,171,183,223,237,265,392$ \\
\hline 43 & 2868 & Heptacosan-10-one & $127,143,155,171,267,283,295,394$ \\
\hline 44 & 2872 & (Z)-9-Nonacosene & 406 \\
\hline 45 & 2900 & Nonacosane $\mathrm{a}^{\mathrm{a}}$ & 408 \\
\hline 46 & 2933 & 15-; 13-; 11-Methylnonacosane & $224 / 225 ; 196 / 197,252 / 253 ; 168 / 169,280 / 281$ \\
\hline 47 & 3000 & Triacontane $\mathrm{e}^{\mathrm{a}}$ & 422 \\
\hline 48 & 3076 & (Z)-9-Hentriacontene & 434 \\
\hline 49 & 3100 & Hentriacontane $\mathrm{a}^{\mathrm{a}}$ & 436 \\
\hline 50 & 3134 & 15-; 13-Methylhentriacontane & $224 / 225,252 / 253 ; 196 / 197,280 / 281$ \\
\hline 51 & 3200 & Dotriacontane $^{\mathrm{a}}$ & 450 \\
\hline 52 & 3275 & (Z)-9-Tritriacontene & 462 \\
\hline 53 & 3300 & Tritriacontane $\mathrm{e}^{\mathrm{a}}$ & 464 \\
\hline
\end{tabular}

$R I$ retention index; $X, Y$ position of the methyl-group or double bond not known; $\Delta$ configuration of the double-bond not known; $N I$ not identified ${ }^{\mathrm{a}}$ Identification with available standards. 
with lithium aluminum hydride (Attygalle 1998; Table 1). (Z)-9-Octadecenylmethylester was characterized by using a commercially available standard (Aldrich). Finally, a compound with a typical sesquiterpene mass spectrum was found in small amounts in the polar fraction of the extract. We could not determine the type of functional group in this sesquiterpene.

Chemical Dimorphism One alkene dominated the composition of the PPG, and surprisingly, this major compound differed among individuals (Fig. 2, Table 2). Among the 37 females whose PPG content was analyzed, 29 had (Z)-9-pentacosene and eight had (Z)-9-heptacosene as their major peak (from here on referred to as the C25- and C27-type, respectively). The frequency of the two types differed significantly from equality $\left(\chi^{2}=15.4, d f=1, P<0.001\right)$. By using exact tests for independent samples to assess whether the proportions of other components were also affected by the major peak, we revealed that 14 of the 21 peaks differed significantly between the C25- and the C27-type (Table 2). Generally, the C27-type had larger proportions of components with longer chain lengths.

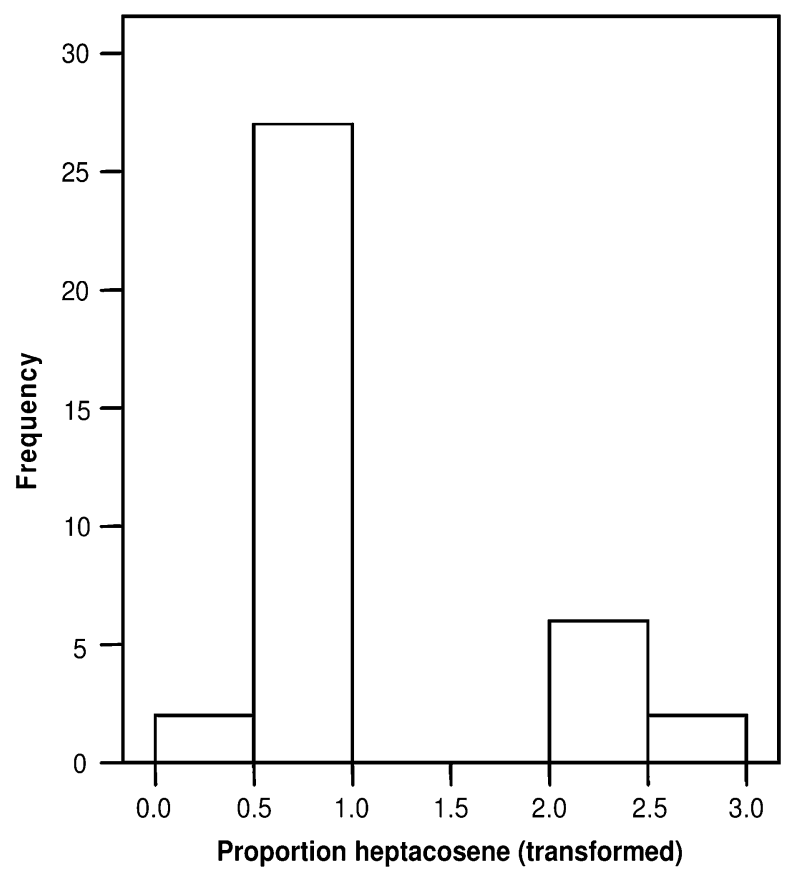

Fig. 2 Frequency distribution (population of $N=37$ ) of individual female European beewolves, Philanthus triangulum, based on the proportion of (Z)-9-heptacosene in their PPG secretion (values transformed to logcontrasts (Aitchison 1986): $Z_{i j}=\log _{10}\left(Y_{i j} / \mathrm{g}\left(Y_{j}\right)\right.$ ) where $Z_{i j}$ is the standardized peak area $i$ for individual $j, Y_{i j}$ is the peak area $i$ for individual $j$, and $g\left(Y_{j}\right)$ is the geometric mean of all peaks for individual $j$ ). There is a clear bimodal distribution, i.e., some individuals have a large proportion of (Z)-9-heptacosene, whereas some have a small proportion; there are no intermediate types

\section{Discussion}

The PPG secretion of beewolf females contains predominantly unbranched unsaturated long chain hydrocarbons (C23-C33, mainly either C25 or C27), smaller amounts of saturated hydrocarbons $(\mathrm{C} 14-\mathrm{C} 33)$, and small or trace amounts of methylalkanes (C17-C31), unsaturated ketones (C23-C27), saturated ketones (C25, C27), a sesquiterpene, an unsaturated $\mathrm{C} 18$ methylester, and an unsaturated $\mathrm{C} 25$ alcohol.

The secretion of the PPG of beewolf females is involved in the preservation of their honeybee prey that serves as larval food (Herzner and Strohm 2007). Females apply large amounts of the PPG secretion to the prey prior to oviposition (Strohm and Linsenmair 2001; Herzner et al. 2007a). The prevalence of unsaturated hydrocarbons in the PPG of beewolf females is probably related to the preservation function. The preservation seems to be mainly accomplished by a physical mechanism (Herzner and Strohm 2007): the secretion prevents the condensation of water on the bees and in this way renders the microclimatic conditions unsuitable for the growth of fungi. Possibly, the PPG secretion covers structures on the paralyzed bee that would otherwise function as effective nuclei for the condensation of water. Scanning electron microscopy revealed that the PPG secretion forms a contiguous layer over the whole surface of the prey (Herzner and Strohm 2007). A hydrocarbon mixture of predominately alkenes might be an ideal means to build up such layers, because at the temperatures that prevail in beewolf brood cells, the unsaturated hydrocarbons might be in a more or less liquid state and can be spread easily over the bee surface.

The composition of hydrocarbons on the cuticle of paralyzed honeybees is dramatically modified due to the treatment by beewolf females (Herzner et al. 2007a, b). Untreated honeybees and most other insects bear predominantly saturated straight or branched hydrocarbons (e.g., Howard and Blomquist 1982, 2005; Schmitt et al. 2007). Less frequently, alkenes constitute large proportions of cuticular hydrocarbons (e.g., on a termite, Howard et al. 1978; on an aphid parasitoid, Liepert and Dettner 1996; on workers of European hornets, Ruther et al. 2002; on stingless bee foragers, Abdalla et al. 2003; on diapausing butterfly pupae, Kaneko and Katagiri 2004; or on nesting females of the burrowing bee, Simmons et al. 2003). The reasons for the prevalence of saturated hydrocarbons in some species and unsaturated hydrocarbons in other species are unknown. Possibly, the physicochemical properties of the surface can be adjusted to specific requirements by a particular mixture of saturated and unsaturated compounds (e.g., Gibbs and Pomonis 1995; Gibbs 1998).

In addition to the ubiquitous alkanes and alkenes that we found in the PPG, we also identified long chain unsaturated 
Table 2 Mean proportions of selected hydrocarbons and ketones from the postpharyngeal glands of individual female European beewolves, $P$. triangulum, that had either (Z)-9-pentacosene (C25-type) or (Z)-9-heptacosene (C27-type) as the major component ${ }^{\mathrm{a}}$

\begin{tabular}{|c|c|c|c|c|c|c|}
\hline \multirow{2}{*}{$\begin{array}{l}\text { Compound name } \\
\text { (Peak no. in Table 1) }\end{array}$} & \multicolumn{2}{|c|}{ C25-type } & \multicolumn{2}{|c|}{ C27-type } & \multirow{2}{*}{$\begin{array}{l}\text { Differences }^{\mathrm{b}} \\
\text { Pent-Hept }\end{array}$} & \multirow[t]{2}{*}{$P$ values } \\
\hline & Mean & $\mathrm{SD}$ & Mean & $\mathrm{SD}$ & & \\
\hline Heneicosane (12) & 0.20 & 0.14 & 0.18 & 0.13 & 0.02 & 0.086 \\
\hline Docosane (13) & 0.16 & 0.09 & 0.13 & 0.08 & 0.04 & 0.001 \\
\hline Tricosenes $(14,15,16)$ & 0.36 & 0.27 & 0.08 & 0.07 & 0.28 & $<0.001$ \\
\hline Tricosane (17) & 14.06 & 3.74 & 12.93 & 3.02 & 1.13 & 0.003 \\
\hline Methyltricosanes $(18,19,20)$ & 0.10 & 0.10 & 0.05 & 0.04 & 0.05 & 0.003 \\
\hline Tetracosene (21) & 1.19 & 0.65 & 0.14 & 0.08 & 1.06 & $<0.001$ \\
\hline Tetracosane (22) & 0.17 & 0.10 & 0.14 & 0.07 & 0.02 & 0.003 \\
\hline Pentacosenes $(25,26)$ & 77.48 & 7.96 & 8.29 & 5.50 & 69.19 & $<\mathbf{0 . 0 0 1}$ \\
\hline Pentacosane (27) & 2.05 & 0.92 & 2.82 & 1.20 & -0.78 & 0.335 \\
\hline Methylpentacosanes (28) & 0.06 & 0.03 & 0.08 & 0.03 & -0.02 & 0.704 \\
\hline Hexacosene (32) & 0.13 & 0.05 & 1.62 & 0.72 & -1.50 & $<0.001$ \\
\hline Hexacosane (33) & 0.05 & 0.03 & 0.05 & 0.02 & 0.00 & 0.067 \\
\hline 16-Pentacosen-8-one (34) & 1.13 & 0.73 & 0.25 & 0.15 & 0.88 & $<0.001$ \\
\hline Heptacosene (36) & 1.00 & 0.39 & 69.80 & 8.86 & -68.80 & $<0.001$ \\
\hline Heptacosane (37) & 0.38 & 0.22 & 0.31 & 0.12 & 0.07 & 0.032 \\
\hline Octacosane (41) & 0.03 & 0.03 & 0.03 & 0.02 & 0.00 & 0.182 \\
\hline 18-Heptacosen-10-one (42) & 1.02 & 5.18 & 1.73 & 0.75 & -0.70 & $<0.001$ \\
\hline Nonacosene (44) & 0.04 & 0.06 & 0.95 & 0.43 & -0.90 & $<\mathbf{0 . 0 0 1}$ \\
\hline Nonacosane (45) & 0.30 & 0.30 & 0.32 & 0.11 & -0.02 & 0.550 \\
\hline Hentriacontene (48) & 0.01 & 0.04 & 0.04 & 0.02 & -0.03 & $<0.001$ \\
\hline Hentriacontane (49) & 0.07 & 0.08 & 0.06 & 0.02 & 0.01 & 0.062 \\
\hline
\end{tabular}

${ }^{a}$ Table entries include mean and one standard deviation (SD) of the proportion (\%) of the components for females of the C25 (N=29) and of the C27-type $(N=8)$, as well as the difference $(\mathrm{C} 25-\mathrm{C} 27)$ and the significance level for the difference according to an exact test $(P$, significant differences in bold).

${ }^{\mathrm{b}}$ Differences were calculated from the original data, rounding of values produced some rounding error.

ketones, some of which had not yet been described as natural products. Only (Z)-18-heptacosen-10-one and 10heptacosanone had previously been reported as components of a contact sex pheromone from females of the white-spotted longicorn beetle, Anoplophora malasiaca (Yasui et al. 2003). The function of these compounds in the secretion of beewolf females is unclear. Besides a not-completely identified sesquiterpene, (Z)-9-octadecenylmethylester, and 16pentacosen-8-ol, these ketones are the only identified components in the PPG of beewolf females that have a functional group. They might be likely candidates to exhibit an antifungal effect. However, in bioassays, no direct antifungal effect of the PPG content could be detected (Herzner et al. 2007a). Male European beewolves have some of the same ketones and a slightly shorter unsaturated ketone in their marking secretion (Schmitt et al. 2003; Kroiss et al. 2006). Their exact function in males is also unknown (see below).

The estimated amount of hydrocarbons in the secretion of the PPG differed considerably among females. This might be due to differences in physiological status, size, and age. Interestingly, the mean (approximately $330 \mu \mathrm{g}$ ) and maximum (approximately 1,400 $\mu \mathrm{g}$ ) amounts match the quantities found on honeybees that were embalmed with the PPG secretion by beewolf females. Bees are each embalmed with approximately $110 \mu \mathrm{g}$ (Herzner et al. 2007a) and females provision on average three bees per day and a maximum of ten bees per day (Strohm and Linsenmair 1997). Thus, an average female has available the necessary amount of PPG secretion for the embalming of the average number of bees caught on 1 day. Likewise, the maximum amount found in some individuals would be sufficient to embalm the maximum number of bees that the most successful females hunt per day. Moreover, according to a three-dimensional reconstruction based on histological sections, the maximum volume of the gland was estimated to be 3-4 $\mu$ l (Strohm et al. 2007). The comparatively large size of the gland is explained by the need to provide enough secretion for the treatment of several prey items per day. The supply with such large amounts of unsaturated hydrocarbons might be costly and might represent a considerable part of the cost of parental care in this species (Strohm and Linsenmair 1999, 2000; Strohm and Marliani 2002).

Remarkably, beewolf females show a striking dimorphism with regard to the chemical composition of the PPG 
secretion. The major component is either (Z)-9-pentacosene or (Z)-9-heptacosene, and there are no intermediate individuals. Both compounds are widespread among aculeate Hymenoptera and other insects (e.g., Ruther et al. 2002; Simmons et al. 2003). Most other components of the PPG secretion also differ between the two morphs, in that C27-types tend to have larger proportions of long-chain compounds. Possibly, the whole metabolism of hydrocarbons is adjusted to longer chain lengths in the C27-types. Why females have either (Z)9-pentacosene or (Z)-9-heptacosene as the major compound is unclear. Preliminary analyses (E. Strohm, G. Herzner, M. Kaltenpoth, unpublished data) suggest that there is no effect of age or physiological status on the expression of the major component. One proximate explanation could be that conditions during development differ between the females and cause differential gene activation [for example, the synthesis of (Z)-9-heptacosene might be induced by high temperatures because of the presumably higher melting point, e.g., Gibbs et al. 1998; Rouault et al. 2000]. However, our study specimens were bred under identical temperature conditions in the same climate chamber with the same diet (honeybees from the same population) and, nevertheless, showed this dimorphism. Furthermore, an analysis of beewolf females from different populations ranging from northern Germany to the southern valleys of the Alps not only showed both types of females, but also revealed that they occurred in similar proportions (Strohm et al. 2008). Together with the lack of intermediate individuals, this might suggest that the dimorphism has a genetic basis. Such a dimorphism would have to be balanced because otherwise one morph would disappear at least from some populations either because it has a selective disadvantage or because of genetic drift. One possible explanation for a balanced dimorphism is a spatial difference in the suitability of the two alleles. Such spatial heterogeneity might either be generated by differences in abiotic or biotic conditions. There are specialized cuckoo wasps that enter the nests and oviposit on the bees (Strohm et al. 2001). These wasps seem to employ chemical mimicry in order not to leave traitorous signs in the nest. Most notably, the chemical mimicry only refers to the C27-type of females (Strohm et al. 2008). Thus, the C27-type might be disadvantaged with regard to the rate of parasitism, but this could be balanced by other advantages. Again, this hypothesis is weakened by the fact that the proportions of both types of individuals are similar over a wide geographical range despite probable differences in the abundance of the cuckoo wasps.

Compared to the content of the PPG of males of the European beewolf (Schmitt et al. 2003; Kroiss et al. 2006), females have fewer components with functional groups and lower proportions thereof, whereas the composition of the alkanes and alkenes is similar. The function of the secretion of the male PPG is also quite different. Males use this secretion to scent mark their territories and to attract receptive females (Simon-Thomas and Poorter 1972; Evans and O’Neill 1988; Strohm 1995; Strohm and Lechner 2000; Schmitt et al. 2003). The marking secretion is stored in and delivered from the PPG (Kroiss et al. 2006). Therefore, the compounds with functional groups may play a role in the attraction of females (Herzner et al. 2005; Kroiss et al. 2006) and may also convey some additional information on male quality and suitability as a mate (Herzner et al. 2006; Kaltenpoth and Strohm 2006).

In summary, females of the European beewolf, $P$. triangulum, have large amounts of mainly unsaturated hydrocarbons in their PPG. The composition of the secretion is probably shaped by its function as an antifungal coating of the prey, paralyzed honeybees. Thus, the function of the PPG of beewolf females differs entirely from this gland in ants. However, the general chemistry is consistent with that found in ants. This supports earlier arguments based on morphology, ultrastructure, and behavioral context (Strohm et al. 2007) that the PPGs of these two taxa are homologous. Comparison of physiological aspects of the PPGs of ants and beewolves, as well as the investigation of other aculeate Hymenoptera is necessary to obtain further insights into the evolution and function of the PPG in this group of insects.

Acknowledgments We are grateful to Gerhard Krammer (Symrise AG) for conducting the GC-FTIR analysis. This study was supported in part by the Deutsche Forschungsgemeinschaft (SFB 554, TP B3, STR 532/1-2).

Open Access This article is distributed under the terms of the Creative Commons Attribution Noncommercial License which permits any noncommercial use, distribution, and reproduction in any medium, provided the original author(s) and source are credited.

\section{References}

Abdalla, F. C., Jones, G. R., Morgan, E. D., and Da, CruzLANDIM, C. 2003. Comparative study of the cuticular hydrocarbon composition of Melipona bicolor Lepeletier, 1836 (Hymenoptera, Meliponini) workers and queens. Genet. Mol. Res. 2:191-199.

Aitchison, J. 1986. The Statistical Analysis of Compositional Data. Chapman and Hall, London.

Attygalle, A. B. 1994. Gas phase infrared spectroscopy in characterization of unsaturated natural products. Pure Appl. Chem. 66:2323-2326.

Attygalle, A. B. 1998. Microchemical techniques, pp. 207-294, in J. G. Millar, and K. F. Haynes (eds.). Methods in Chemical Ecology: Chemical Methods. Kluwer Academic Press, New York.

Carlson, D. A., Bernier, U. R., and Sutton, B. D. 1998. Elution patterns from capillary $\mathrm{GC}$ for methyl-branched alkanes. $J$. Chem. Ecol. 24:1845-1865. 
DAhBI, A., CERDA, X., and LenOIR, A. 1998. Ontogeny of colonial hydrocarbon label in callow workers of the ant Cataglyphis iberica. C. R. Acad. Sci. Sér. 3 Sci. Vie 321:395-402.

Dunkelblum, E., Tan, S. H., and SilK, P. J. 1985. Double-bond location in monosaturated fatty acids by dimethyl sulfide derivatization and mass spectrometry: Application to analysis of fatty acids in pheromone glands of four Lepidoptera. J. Chem. Ecol. 11:265-277.

Eelen, D., Børgesen, L., and BiLlen, J. 2006. Functional morphology of the postpharyngeal gland of queens and workers of the ant Monomorium pharaonis (L.). Acta Zool. 87:101-111.

Evans, H., and O'NEILL, K. 1988. The Natural History of North American Beewolves. Cornell University Press, Ithaca, New York.

GIBBS, A. G. 1998. Water-proofing properties of cuticular lipids. Am. Zool. 38:471-482.

GIBBS, A., and POMONIS, J. G. 1995. Physical properties of insect cuticular hydrocarbons - the effects of chain-length, methylbranching and unsaturation. Comp. Biochem. Physiol. B-Biochem. Mol. Biol. 112:243-249.

GibBS, A. G., Louie, A. K., and Ayala, J. A. 1998. Effects of temperature on cuticular lipids and water balance in a desert Drosophila: is thermal acclimation beneficial? J. Exp. Biol. 201:71-80.

Hefetz, A., Errard, C., and Cojocaru, M. 1992. Heterospecific substances in the postpharyngeal gland secretion of ants reared in mixed groups. Naturwissenschaften 79:417-420.

Hefetz, A., Errard, C., Chambris, A., and Le Negrate, A. 1996. Postpharyngeal gland secretions as a modifier of aggressive behavior in the myrmicine ant Manica rubida. J. Ins. Behav. 9:709-717.

Herzner, G., and Strohm, E. 2007. Fighting fungi with physics prey embalming by a solitary wasp prevents water condensation. Curr. Biol. 17:R46-R47.

Herzner, G., Schmitt, T., Linsenmair, K. E., and Strohm, E. 2005. Prey recognition by females of the European beewolf and its potential for a sensory trap. Anim. Behav. 70:1411-1418.

Herzner, G., Schmitt, T., Heckel, F., Schreier, P., and Strohm, E. 2006. Brothers smell similar: variation in the sex pheromone of male European beewolves Philanthus triangulum F. (Hymenoptera: Crabronidae) and its implications for inbreeding avoidance. Biol. J. Linn. Soc. 89:433-442.

Herzner, G., Schmitt, T., Peschke, K., Hilpert, A., and Strohm, E. 2007a. Food wrapping with the postpharyngeal gland secretion by females of the European beewolf Philanthus triangulum. J. Chem. Ecol. 33:849-859.

Herzner, G., Goettler, W., Kroiss, J., Purea, A., Webb, A. G., JAKOB, P. M., RÖSSLER, W., and STROHM, E. 2007b. Males of a solitary wasp possess a postpharyngeal gland. Arth. Struc. Dev. 36:123-133.

Hölldobler, B., and Wilson, E. O. 1990. The Ants. Springer, Heidelberg, Germany.

Howard, R. W., and BlomQuist, G. J. 1982. Chemical ecology and biochemistry of insect hydrocarbons. Annu. Rev. Entomol. 27:149-172.

HowARD, R. W., and BlomQUist, G. J. 2005. Ecological, behavioral, and biochemical aspects of insect hydrocarbons. Annu. Rev. Entomol. 50:371-391.

Howard, R. W., McDaniel, C. A., and Blomeuist, G. J. 1978. Cuticular hydrocarbons of the eastern subterranean termite, Reticulitermes flavipes (Kollar) (Isoptera: Rhinotermitidae). J. Chem. Ecol. 4:233-245.

KaltenPoth, M., and Strohm, E. 2006. The scent of senescence: Age-dependent changes in the composition of the cephalic gland secretion of the male European beewolf, Philanthus triangulum. J. Ins. Sci. 6:20.

KANEKo, J., and KatagiRI, C. 2004. Epicuticular wax of large and small white butterflies, Pieris brassicae and P. rapae crucivora: qualitative and quantitative comparison between diapause and non-diapause pupae. Naturwissenschaften 91:320-323.

Kroiss, J., Schmitt, T., Schreier, P., Strohm, E., and HerzNer, G. 2006. A postpharyngeal gland functions as a sex pheromone reservoir in males of the solitary wasp Philanthus triangulum. J. Chem. Ecol. 32:2763-2776.

Lenoir, A., Fresneau, D., Errard, C., and Hefetz, A. 1999. Individuality and colonial identity in ants: the emergence of the social representation concept, pp. 219-237, in C. Detrain, C. J. L. Deneubourg, and J. M. Pasteels (eds.). Information Processing in Social Insects. Birkhäuser Verlag, Basel.

Lenoir, A., Hefetz, A., Simon, T., and Soroker, V. 2001. Comparative dynamics of gestalt odour formation in two ant species Camponotus fellah and Aphaenogaster senilis (Hymenoptera: Formicidae). Physiol. Entomol. 26:275-283.

LIEPERT, C., and DETTNER, K. 1996. Role of cuticular hydrocarbons of aphid parasitoids in their relationship to aphid-attending ants. J. Chem. Ecol. 22:695-707.

Melo, G. A. R. 1999. Phylogenetic relationships and classification of the major lineages of Apoidea (Hymenoptera), with emphasis on the crabronid wasps. Scientific papers, Nat. Hist. Mus. Univ. Kans. 14:1-55.

Oldham, N. J., Morgan, E. D., Agosti, D., and Wehner, R. 1999. Species recognition from postpharyngeal gland contents of ants of the Cataglyphis bicolor group. J. Chem. Ecol. 25:1383-1393.

RouAult, J., CAPY, P., and JALLON, J. -M. 2000. Variations of male cuticular hydrocarbons with geoclimatic variables: an adaptative mechanism in Drosophila melanogaster? Genetica 110:117130.

Ruther, J., Sieben, S., and Schricker, B. 2002. Nestmate recognition in social wasps: manipulation of hydrocarbon profiles induces aggression in the European hornet. Naturwissenschaften 89:111-114.

Schmitt, T., Strohm, E., Herzner, G., Bicchi, C., Krammer, G., Heckel, F., and SchreIER, P. 2003. (S)-2,3-Dihydrofarnesoic acid, a new component in cephalic glands of male European beewolves Philanthus triangulum. J. Chem. Ecol. 29:24692479.

Schmitt, T., Herzner, G., Schreier, P., and Strohm, E. 2007. Volatiles of foraging honeybees Apis mellifera L. (Hymenoptera: Apidae) and their possible role as semiochemicals and kairomones. Apidologie 38:164-170.

SCHOETERS, E., and BILlen, J. 1997. The post-pharyngeal gland in Dinoponera ants (Hymenoptera: Formicidae): unusual morphology and changes during the secretory process. Int. J. Insect Morph. Embryol. 26:443-447.

Simmons, L. W., AlCOCK, J., and EEDER, A. 2003. The role of cuticular hydrocarbons in male attraction and repulsion by female Dawson's burrowing bee, Amegilla dawsoni. Anim. Behav. 66:677-685.

Simon-Thomas, R. T., and Poorter, E. P. R. 1972. Notes on the behavior of males of Philanthus triangulum (F.) (Hymenoptera, Sphecidae). Tijdschr. Entomol. 115:141-151.

SOROKER, V., and HEFETZ, A. 2000. Hydrocarbon site of synthesis and circulation in the desert ant Cataglyphis niger. J. Ins. Physiol. 46:1097-1102.

SoroKer, V., VIENNE, C., and HefETZ, A. 1994. The postpharyngeal gland as a "Gestalt" organ for nestmate recognition in the ant Cataglyphis niger. Naturwissenschaften 81:510-513.

Soroker, V., Hefetz, A., Cojocaru, M., Billen, J., Franke, S., and FRANCKE, W. 1995. Structural and chemical ontogeny of the postpharyngeal gland in the desert ant Cataglyphis niger. Physiol. Entomol. 20:323-329.

SOROKER, V., FresneAU, D., and HefetZ, A. 1998. Formation of colony odor in ponerine ant Pachycondyla apicalis. J. Chem. Ecol. 24:1077-1090. 
SPSS INC 2004. SPSS 13.0 for windows. SPSS Inc, Chicago, IL.

Stein, S., Mirokhin, Y., TcheKhovsKoi, D., and Mallard, G. 2001. The NIST Mass Spectral Search Program for the NIST/ EPA/NIH Mass Spectral Library (Version 2.0). Gaithersburg, MD, USA.

STROHM, E. 1995. Allokation elterlicher Investitionen beim Europäischen Bienenwolf Philanthus triangulum Fabricius (Hymenoptera: Sphecidae). Verlag Dr. Köster, Berlin.

Strohm, E., and LeCHNER, K. 2000. Male size does not affect territorial behaviour and life history traits in a sphecid wasp. Anim. Behav. 59:183-191.

Strohm, E., and LinsenmaIR, K. E. 1994/95. Leaving the cradle: how beewolves (Philanthus triangulum F.) obtain the necessary spatial information for emergence. Zoology 98:137-146.

StroHM, E., and LinSENMAIR, K. E. 1997. Female size affects provisioning and sex allocation in a digger wasp. Anim. Behav. 54:23-34.

STROHM, E., and LINSENMAIR, K. E. 1999. Measurement of parental investment and sex allocation in the European beewolf Philanthus triangulum F. (Hymenoptera: Sphecidae). Behav. Ecol. Sociobiol. 47:76-88.

Strohm, E., and Linsenmair, K. E. 2000. Allocation of parental investment among individual offspring in the European beewolf Philanthus triangulum F. (Hymenoptera: Sphecidae). Biol. J. Linn. Soc. 69:173-192.
Strohm, E., and Linsenmair, K. E. 2001. Females of the European beewolf preserve their honeybee prey against competing fungi. Ecol. Entomol. 26:198-203.

Strohm, E., and Marliani, A. 2002. The cost of parental care: prey hunting in a digger wasp. Behav. Ecol. 13:52-58.

Strohm, E., Laurien-Kehnen, C., and Bordon, S. 2001. Escape from parasitism: Spatial and temporal strategies of a sphecid wasp against a specialised cuckoo wasp. Oecologia 129:50-57.

Strohm, E., Herzner, G., and Goettler, W. 2007. A 'social' gland in a solitary wasp? The postpharyngeal gland of female European beewolves (Hymenoptera, Crabronidae). Arthr. Struct. Dev. 36:113-122.

Strohm, E., Kroiss, J., Herzner, G., Laurien-Kehnen, C., Boland, W., SchreIER, P., and Schmitt, T. 2008. A cuckoo in wolves' clothing? Chemical mimicry in a specialized cuckoo wasp of the European beewolf (Hymenoptera, Chrysididae and Crabronidae). Front. Zool. 5:2

Vienne, C., Soroker, V., and Hefetz, A. 1995. Congruency of hydrocarbon patterns in heterospecific groups of ants: transfer and/or biosynthesis? Ins. Soc. 42:267-277.

YAsui, H., Akino, T., YASUda, T., FUKAYA, M., ONO, H., and WAKAMURA, S. 2003. Ketone components in the contact sex pheromone of the white-spotted longicorn beetle, Anoplophora malasiaca, and pheromonal activity of synthetic ketones. Entomol. Exp. Appl. 107:167-176. 